\title{
Preliminary risk assessment of ecotoxic substances accidental releases in major risk installations through fuzzy logic
}

\author{
R.M. Darbra ${ }^{a, *}$, M. Demichela ${ }^{b}$, S. Murè $\grave{c}^{c}$ \\ ${ }^{a}$ Centre d'Estudis del Risc Tecnològic (CERTEC), Department d'Enginyeria Quimica, Universitat Politècnica de Catalunya, Diagonal 647, \\ 08028 Barcelona, Catalonia, Spain \\ ${ }^{\mathrm{b}}$ SAfeR-Centro Studi su Sicurezza, Affidabilità e Rischi, Dipartimento di Scienza dei Materiali e Ingegneria Chimica-Politecnico di Torino, \\ Corso Duca degli Abruzzi, 24, 10129 Torino, Italy \\ ${ }^{c}$ ARIA s.r.l.-Analisi dei Rischi Industriali e Ambientali, Via P.C. Boggio, 61, 10138 Torino, Italy
}

\section{A R T I C L E I N F O}

Article history:

Received 27 December 2006

Accepted 1 July 2007

Keywords:

Preliminary risk assessment

Fuzzy logic

Ecotoxic substances

\begin{abstract}
A B S T R A C T
In the present work a fuzzy logic model to preliminary assess the risk of accidental releases of ecotoxic substances in hazard plants has been developed. The methodology is based in three steps, the characterization of the hazardousness of the substance, the delimitation of the soil and groundwater vulnerability and the identification of the protective and preventive measures of the plant. The tool has been tested with a set of storage yards of ecotoxic substances, mainly oil, in the Regione Piemonte area (Italy). The results obtained are in good agreement with the real situation of the surveyed storage yards. Thus, by using this methodology it is possible to preliminary assess the risk from uncertain data.
\end{abstract}

(C) 2007 The Institution of Chemical Engineers. Published by Elsevier B.V. All rights reserved.

\section{Introduction}

The Council Directives 96/82/EC (Seveso II Directive, 1996) and 2003/105/EC (Seveso III Directive, 2003) concerning the control of major accidents hazards involving dangerous substances (the Seveso Directives) aim at preventing major accidents that could harm both people living or working around industrial establishments and the environment. The first one, in particular, introduces the substances that are considered to be dangerous for the environment. As a consequence, the competent Authorities in charge of applying such directive have to assess the environmental impact resulting from major accidents.

Here the problem is that the methodologies to assess the risk related to the release of dangerous substances for the environment in soil and water are very complex and require a lot of data to be applied.

For a complete risk assessment in case of ecotoxic substances, traditionally based on cost-benefit analysis, and only recently integrated in a multi-criteria decision analysis (Khadam and Kaluarachchi, 2003), it is necessary to deal with a great amount of data, not only for the categorization of the substances but also for the plant (protective/preventive measures) and soil characterization (Chen et al., 1998).

Often, the data available are qualitative, vague and imprecise, and the effort to obtain more precise data can result very expensive both in term of time and money (Lark and Bolam, 1997).

In early works, some efforts have been made to develop a simplified but reliable risk assessment methodology (Orso Giacone et al., 2004; Demetri et al., 2003), resulting in a ranking method able to support the decision making about the adequateness of preventive and protective measure, with respect to the vulnerability of the site, or the need of performing more detailed analysis. This method was found to be very effective in classifying extreme situations (very low or very high risk), but with a low sensitivity to intermediate situations, mainly due to the uncertainties in the input data. In the present study, also given the results of previous efforts, fuzzy logic is used to develop a model able to deal with those uncertainties.

\footnotetext{
* Corresponding author.

E-mail address: rmdarbra@yahoo.es (R.M. Darbra). 0957-5820/\$ - see front matter (C) 2007 The Institution of Chemical Engineers. Published by Elsevier B.V. All rights reserved. doi:10.1016/j.psep.2007.10.015
} 


\section{Nomenclature}

A fuzzy subset of $X$

$d$ degradability of the substance

$m \quad$ mobility of the substance

M protective/preventive measures

$p \quad$ permeability

$R \quad$ risk function

S soil or groundwater vulnerability

$\mathrm{S} \quad$ hazardousness of the substance

$t \quad$ toxicity

V vulnerability

$w \quad$ groundwater depth

$x \quad$ element of the $X$ set

$X \quad$ finite set of objects

$\mu_{\mathrm{A}}(\mathrm{x}) \quad$ grade of membership of element $\mathrm{x}$ in fuzzy subset $A$

Fuzzy logic is actually used to quantify the vagueness and imprecision of the interpretations (Mays et al., 1997). Fuzzy systems are particularly useful to solve complex problems that, even if not referable to an algorithm, can be qualitatively described using linguistic expressions (Zadeh, 1965). A number of applications has been developed to face different environmental problems, as detailed in the following sections.

Present application constitutes a preliminary risk assessment tool able to support decision making for the management of ecotoxic substances in major risk installations.

The methodology involves three steps. In all of them, the main characteristic is that the variables involved do not have sharply defined boundaries:

- first of all, the characterization of the substance involved in the industrial accident: its hazard depends on its mobility, its toxicity and its degradability;

- secondly, the vulnerability of the soil (e.g. permeability) and the groundwater (e.g. depth);

- and thirdly, the management and plant measures to protect the environment and the people in the area (i.e. level of safety that they guarantee).

Once each of these steps has been completed by fuzzy logic application, a four level categorization of the risk of the plant is achieved: inert (very low), low, medium and high risk.

In this paper, fuzzy logic is applied to a specific case: the risk analysis of a set of storage yards, in the Regione Piemonte area (Italy) where several reference accidental scenarios involving ecotoxic substances have been identified. Four of these plants, different in extent and quality of the management, have been also submitted to an in-depth survey, in order to verify the information otherwise obtained from the risk assessment documents developed by the stakeholder.

This methodology was developed to be a tool for both public authorities and plant manager, as a support in risk informed decision making.

\section{Fuzzy logic}

Fuzzy systems are not a new concept; the fuzzy set theory has provided consistent and proven means to model many realworld systems as industrial plants, electrical devices, risk assessment (Chen and Pham, 2001) and, recently, occupational accidents analysis (Murè et al., 2004). In particular, with reference to environmental subjects the following papers were used as reference.

Lehn and Temme (1996) developed a fuzzy tool to classify potentially contaminated sites in Germany. In 1998 Van der Werf and Zimmer proposed a fuzzy indicator of the environmental impact of pesticides used in agriculture. In 1999 Mohamed and Côté developed a decision analysis-based model to assess the risk posed to human health from polluted sites, where the uncertainties in the input parameters were represented by fuzzy numbers. In $2003 \mathrm{Hu}$ et al. developed a tool for the selection of remediation techniques for petroleum contaminated sites, where the site characterization where performed through a fuzzy logic-based subsystem. In the end, in 2004 Uricchio et al. proposed a decision support system, based on fuzzy logic, for groundwater pollution risk evaluation.

Fuzzy logic uses linguistic variables in place and/or in addition to numerical ones. The linguistic variable is a variable which values are sentences in a natural or artificial language. Fuzzy logic is a decisional system based on rules such as "if ... then ... else". Whereas for the classic logic every proposition must either be "true" or "false", for the fuzzy logic an affirmation can be simultaneously "true" or "false", with a certain degree of membership to each class (Mc Bratney and Inakwu, 1997).

A fuzzy set is a class of objects with a continuum of grades of membership defined for a given interval. Such a set is characterized by a membership function that assigns a degree of membership ranging between zero and one to each object (Leondes, 1999).

In a formal definition of a fuzzy set, it can be said that $X$ is a finite set (or space) of points, which could be elements, objects or properties:

$\mathrm{X}=\mathrm{x}_{1}, \mathrm{x}_{2}, \ldots, \mathrm{x}_{n}$

where $x_{i}$ are the elements that constitute the set. Each element $x_{i}$ has a particular membership value $\mu_{i}$, which represents its grade of membership in a fuzzy set. The set of membership values $\mu_{\mathrm{i}}$ associated with the fuzzy set occur along the continuum $[0,1]$. A fuzzy subset $A$ of $X$ can thus be represented as a linear combination of the following form:

$\mathrm{A}=\mu_{\mathrm{A}}\left(x_{1}\right), \mu_{\mathrm{A}}\left(x_{2}\right), \ldots, \mu_{\mathrm{A}}\left(x_{n}\right)$

The interval, over which a fuzzy subset applies, is thus characterized by a membership function that associates each element $x_{i}$ of $X$ with a degree of membership $\mu_{\mathrm{A}}$ to A.

\section{Methodology}

\subsection{Selection of variables}

As can be seen in Fig. 1, there are many parameters involved in the risk assessment of release of ecotoxic substances in a hazardous plant. Three big macro-variables should be identified in order to carry out a proper risk assessment: the hazardousness of the substance, the vulnerability of the soil or the groundwater and the protective/preventive measures taken in order to protect the environment.

The hazardousness of the substances depends on several factors and at the same time these ones depend on others. The information required to carry out a complete risk assessment 


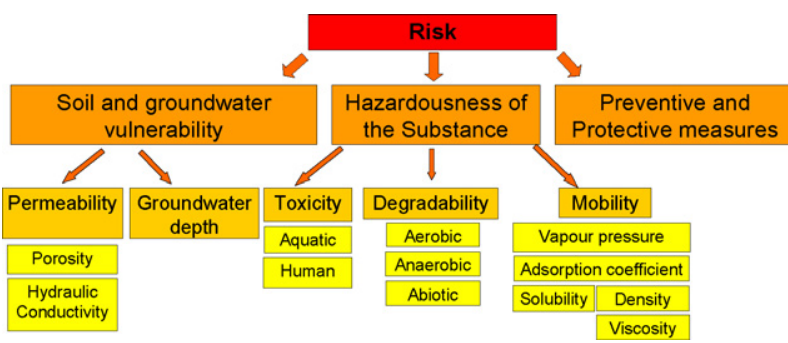

Fig. 1 - Risk assessment scheme for releases of ecotoxic substances in hazard plants.

is often not available and/or expensive to obtain, both in terms of time and money. As an example, there are a set of parameters such as the solubility, density, etc., that can be found in the safety cards of the substances, but other such as adsorption coefficient and hydrolysis decay (abiotic degradability) are not so easy to attain by the user of the tool.

Thus the fuzzy model was rearranged in order to be based on a reduced number of input variables: in practice, microvariables (light grey boxes in Fig. 1) have been grouped in macro-variables, as detailed later.

The fact that the information required by fuzzy logic is more qualitative than quantitative makes this tool a good candidate to be used in order to preliminary assess the risk of soil and water pollution in hazardous plants. Moreover, the creation of a fuzzy model with this purpose will help the manager of the plant to use the methodology in a more easy and effective way.

\subsection{Fuzzy process}

As it can be seen in Fig. 2, the proposed fuzzy model consists of different steps. During the first stage, the inputs and outputs must be defined and then converted from values to linguistic parameters by creating fuzzy sets for each of them (fuzzification process). Secondly, a set of rules must be established. These rules will allow going from the input to the output. But now the process has to be inverted: from the linguistic parameter it is necessary to attain a crisp numeric value by the defuzzification process (centroid method). Finally, an output is obtained which is directly related with a certain level of risk. All these steps are carried out using the fuzzy toolbox present in Matlab 6.0 and they are explained hereafter.

\subsubsection{Inputs definition}

3.2.1.1. Characterization of the substance (S). In order to identify the substances that may pose an important risk to both humans and the environment, it is necessary to have

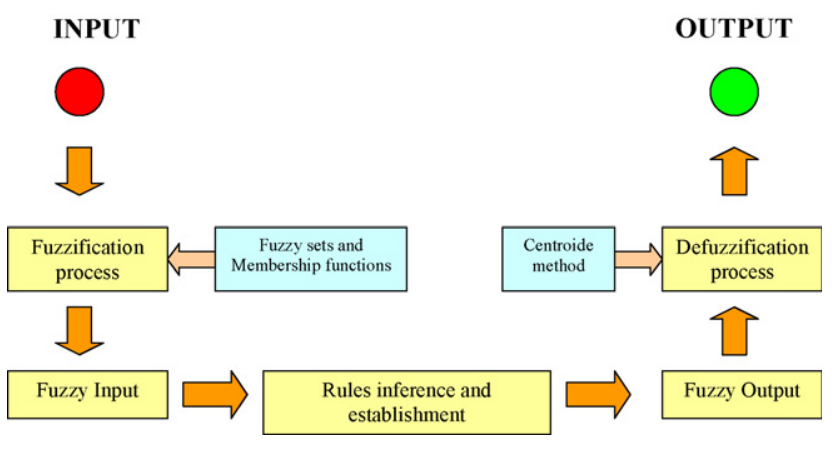

Fig. 2 - Representation of the fuzzy methodology. information about relevant parameters according to their capability of endangering the subsoil and the groundwater quality. The range of such substances that are present in industrial plants is very wide, for this reason this study focuses on those substances that may pose a risk for the environment according to the European Directive 67/548/CEE, classified with risk phrases R50-R51/R53.

The hazardousness of a substance depends on its properties. As far as the hazard they might present to the soil and groundwater is concerned, the following parameters should be considered:

- Toxicity (t) including human related properties (e.g. carcinogenicity) and toxicity as far as the ecosystem in the subsoil and groundwater is concerned (e.g. toxic for aquatic organisms).

- Mobility $(m)$ in the soil and in the aquifer. This parameter depends at the same time on a set of properties such as density of the substance, its solubility, adsorption coefficient, cinematic viscosity, vapour tension.

- Degradability (d):

(a) Biodegradability: aerobic (measured by DOC (dissolved organic carbon) and TOD (total organic carbon)) and anaerobic (measured by methane production).

(b) Abiotic degradability (measured by the hydrolysis duration).

3.2.1.2. Soil and ground water vulnerability (V). In risk analysis the characterization of the area where the accidental pollution may occur is very important. The principal hydro-geological characteristics of the area and the dominant lithology of the soil should be known to define the vulnerability of the soil and the groundwater. The parameters chosen to delimitate these factors are:

- Permeability $(p)$ : it depends on the porosity of the soil and its hydraulic conductivity. According to the grade of permeability of the soil the substance may reach the aquifer or not, so this is important information in order to determine the risk for the environment.

- Depth of the groundwater $(w)$ : the deeper the aquifer is, the less dangerous the contamination will be since the substance will have more problems to get the groundwater.

3.2.1.3. Protective/preventive measures (M). A part from the characterization of the substance and also of the soil and groundwater, it is very important to know if the plant is taking any kind of preventive/protective measures in order to minimize the environmental impact of a possible accident. Depending on the type of release scenario the measures to be taken will be different. Four types of release scenarios were considered:

- underground pipelines and tanks;

- atmospheric and pressure tanks and containers;

- pipelines;

- big bags, bulk containers moved by a stacker, during loading/unloading operations.

According to each scenario a reference set of protective/ preventive measures has been defined and categorized on the basis of the risk level. From this, it is possible to determine the adequateness of protective/preventive measures to protect the environment. 


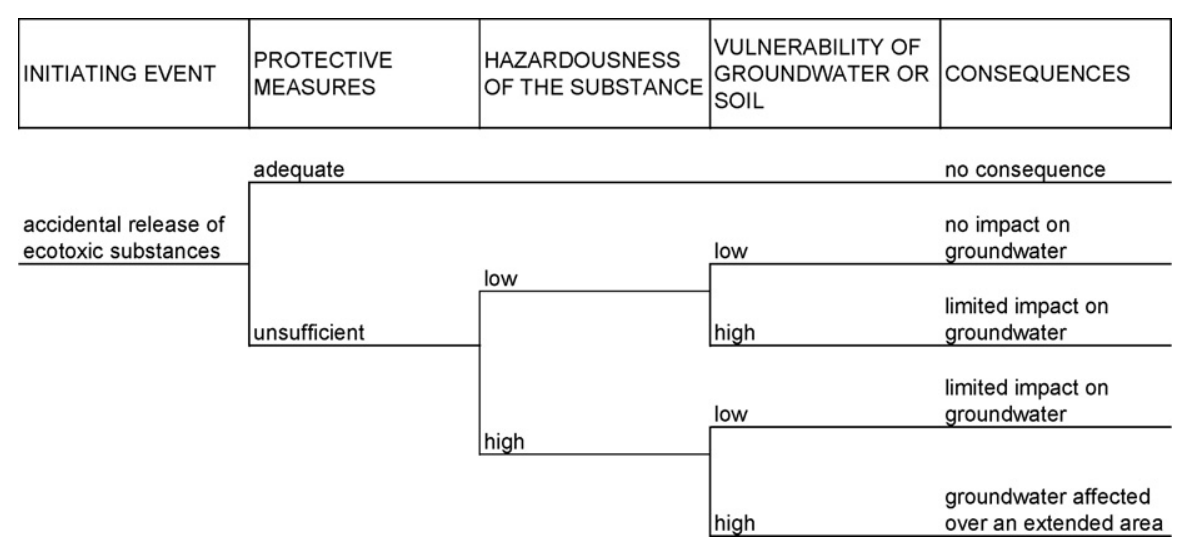

Fig. 3 - Event Tree describing the effects of the model variables in case of accidental release of ecotoxic substances.

\subsubsection{Output definition}

The main output of this fuzzy model is the risk level for each of the surveyed plants and situations. A function to attain the final value of this risk can be established (1). The value obtained must be defuzzificated in order to give an understandable assessment of the risk.

3.2.2.1. Risk function. In order to assess the risk of releases of ecotoxic substances in hazard plants the risk was defined as follows:

$\mathrm{R}=\mathrm{S} \times \mathrm{V} \times \mathrm{M}$

with S: hazardousness of the substance; V: soil and ground water vulnerability; $M$ : protective/preventive measures taken in order to minimize the environmental impact of a hypothetical accident.

It is important to notice that, on the contrary of $\mathrm{M}, \mathrm{S}$ and $\mathrm{V}$ are macro-variables, since they are functions of other parameters.

\subsubsection{Substance hazardousness function.}

$S=t \times m \times d$

where $t$ is the toxicity, $m$ the mobility and $d$ is the degradability of the substance.

\subsubsection{Vulnerability function.}

$\mathrm{V}=p \times w$

where $p$ is the permeability of the soil and $w$ the groundwater depth.
The outputs coming from the hazardousness function and vulnerability function turn into the input for the risk function.

The macro-variables and their effect on the final event consequences are shown in Fig. 3, through a Event Tree (Papazoglou, 1998), tool able to illustrate the sequences that from a initiating event, in this case the accidental release of ecotoxic substances, bring to the possible consequences, given the environmental and technical conditions present in the plant.

\subsubsection{Fuzzy sets and intervals}

For all the inputs and outputs, the fuzzy sets have been established. In most cases the used fuzzy sets have been: low, medium, high, associated to a quantitative description ranging from 0 to 10 . But there have been cases where this classification has been altered in order to facilitate the methodology for the user. For example, in the case of the permeability of the soil, it was difficult for the user to know the data on the corresponding inputs (porosity and hydraulic conductivity) without performing an expensive soil characterization, thus it was decided to establish four categories of permeability according to the soil particle size distribution, a parameter directly observable by the user. A similar process was undertaken to categorize other inputs on which there are limited data, as the mobility (examples in Table 1).

With reference to the protective and preventive measures, users can determine the adequateness of protective/preventive measures taken in their plants from a reference table ad hoc developed, where the measures have been classified according to the kind of equipment involved in the accidental event and according the level of risk. Table 2 shows the reference data used in the present study.

Finally, with all the inputs and with the use of the fuzzy model it is possible to attain a final result for the second level

\section{Table 1 - Fuzzy sets for the inputs}

\begin{tabular}{lcccr} 
General inputs & Low & Medium & High \\
\hline $0-10$ & Hydrocarbons & $0-4$ & $2-8$ & $6-10$ \\
Mobility & $0-4$ & Pesticides and herbicides & Salts \\
\hline $0-10$ & Claim (low) & Slime (medium) & $2-8$ & $6-10$ \\
Permeability & $0-2.5$ & $1.5-5.5$ & Sand (high) & Gravel (very high) \\
\hline $0-10$ & & $3.5-7.5$ & $6.5-10$ \\
\hline
\end{tabular}


Table 2 - Classification of preventive and protective measures adopted as reference in the present study

\begin{tabular}{|c|c|c|}
\hline $\begin{array}{l}\text { Equipment } \\
\text { (Scenario) }\end{array}$ & Risk level & Reference preventive and protective measures \\
\hline \multirow{3}{*}{$\begin{array}{l}\text { Atmospheric } \\
\text { tanks }\end{array}$} & Low & $\begin{array}{ll}\text { - } & \text { Cathodic protection } \\
\text { - } & \text { Containment basin } \\
\text { - } & \text { Level indication }\end{array}$ \\
\hline & Medium & $\begin{array}{ll}\text { - } & \text { Rust preventer application } \\
\text { - } & \text { Vitrification of tank walls }\end{array}$ \\
\hline & High & $\begin{array}{ll} & \text { High and very high level alarm } \\
\text { - } & \text { High level interlock systems } \\
\text { - } & \text { Valve operated by remote control } \\
\text { - } & \text { Pressure sealing test }\end{array}$ \\
\hline \multirow{3}{*}{$\begin{array}{l}\text { Underground } \\
\text { tanks }\end{array}$} & Low & $\begin{array}{l}\text { - tank with "double wall" structure } \\
\text { - level indicator } \\
\text { - Vitrification of tank walls }\end{array}$ \\
\hline & Medium & 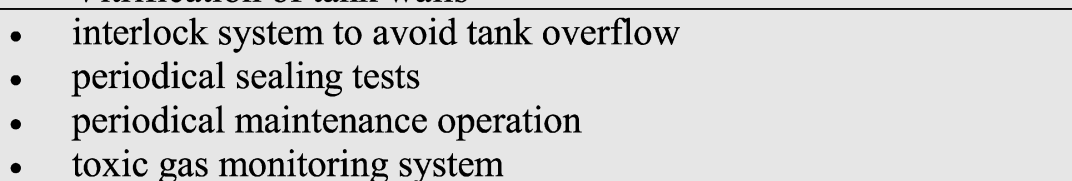 \\
\hline & High & $\begin{array}{l}\text { - } \quad \text { continuous monitoring system for accidental leakages } \\
\text { - } \quad \text { underground barrier with water-bearing stratum captation } \\
\text { - } \quad \text { barrier walls in clay or other materials for oil absorbing }\end{array}$ \\
\hline \multirow{3}{*}{ piping } & Low & $\begin{array}{l}\text { - } \quad \text { Coating with bituminous band for underground piping } \\
\text { - } \quad \text { Sealing test with penetrating liquids }\end{array}$ \\
\hline & Medium & $\begin{array}{l}\text { - Intercepting valves for isolation purposes } \\
\text { - Shock adsorbers for water hammer }\end{array}$ \\
\hline & High & $\begin{array}{l}\text { - Underground barrier with water-bearing stratum captation } \\
\text { - } \quad \text { Cloth in oil absorbing materials }\end{array}$ \\
\hline \multirow{3}{*}{$\begin{array}{c}\text { Loading } \\
\text { unloading area }\end{array}$} & Low & $\begin{array}{l}\text { - Concrete flooring } \\
\text { - Floors with adequate slope and canalization/collecting systems in } \\
\text { case of accidental release }\end{array}$ \\
\hline & Medium & $\begin{array}{l}\text { - Sump pit for meteoric waters with oil separation } \\
\text { - Sewer trunk line for water and oil mixture and backwashing plant } \\
\text { - Overfilling system with optical probes for tanker }\end{array}$ \\
\hline & High & $\begin{array}{l}\text { - Underground barrier with water-bearing stratum captation } \\
\text { - } \quad \text { Cloth in oil absorbing materials }\end{array}$ \\
\hline
\end{tabular}

Table 3 - Risk interpretation scheme

\begin{tabular}{|c|c|c|}
\hline Risk & Environmental impact & Risk management measures \\
\hline Neglectable & No environmental impact & $\begin{array}{l}\text { Damages to the environment and to human health are negligible } \\
\text { if the safety levels are maintained in time and a correct management } \\
\text { system is implemented }\end{array}$ \\
\hline Low & Potential environmental impact & $\begin{array}{l}\text { The three variables }(\mathrm{M}, \mathrm{V}, \mathrm{S}) \text { are compensated one with the others. } \\
\text { Any of them is so important to make the situation extreme. But it is important } \\
\text { to keep update the protective/preventive measures }\end{array}$ \\
\hline Medium & Significant potential pollution & $\begin{array}{l}\text { The characteristics of the soil and sub-soil and of the substance determine } \\
\text { the possibility of causing significant pollution. The measures are } \\
\text { very important at this stage }\end{array}$ \\
\hline High & Significant pollution & $\begin{array}{l}\text { The hydro-geological characteristics of the site determine a high } \\
\text { probability of significant pollution to vulnerable environmental and territorial } \\
\text { elements in the case of accidental spill }\end{array}$ \\
\hline
\end{tabular}




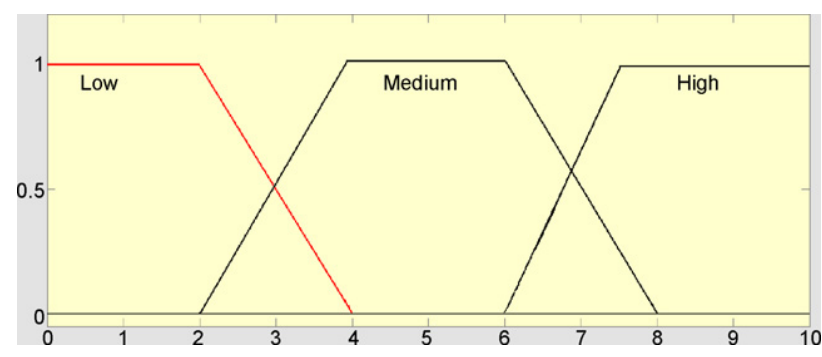

Fig. 4 - Fuzzy subsets for a generic variable (membership functions).

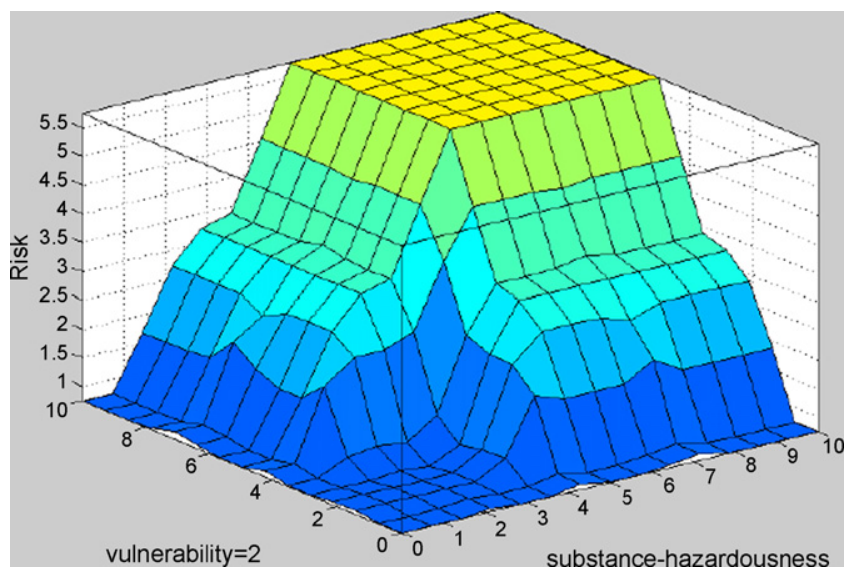

Fig. 5 - Three-dimensional representation of the risk, vulnerability and substance hazardousness.

output, this is the risk of the plant. Four fuzzy sets have been established to define this parameter. Their interpretation is explained in Table 3, including some recommendations for each case.

\subsubsection{Membership functions}

A fuzzy membership function is an expression defining the grade of membership of an element $x$ in a set $A$ (according what has been explained in Section 2). In contrast to the characteristic function in conventional set theory which implies that membership of individual objects in a subset as either belonging or not at all, the membership function of $x$ in $A$ is expressed as:

$\mu_{\mathrm{A}}(\mathrm{x}) \rightarrow[0,1]$

that associates with each element $x \in X$ its grade of membership $\mu_{\mathrm{A}}(\mathrm{x}) \in[0,1]$. Thus

$\mu_{\mathrm{A}}(\mathrm{x})=0$ means that $\mathrm{x}$ does not belong to the subset $\mathrm{A}$,

$\mu_{\mathrm{A}}(\mathrm{x})=1$ indicates that $\mathrm{x}$ fully belongs, and

$0<\mu_{A}(x)<1$ means that $x$ belongs to some degree to A; partial membership is therefore possible (Mc Bratney and Inakwu, 1997).

Membership functions are a characteristic of the data set under analysis and can take on many forms (Cox, 1994). In the present work, a set of trapezoidal functions has been used in order to define the behaviour of the variables. This decision has been taken after the practical application of different types of functions to the parameters. It has been seen that the trapezoidal function was the most suitable one according to the quality of the information and the knowledge of the parameters (see Fig. 4).

\subsubsection{Setting up the rules}

Fuzzy logic is a decisional system based on linguistic rules. Therefore, once the membership functions have been defined for all the fuzzy sets it is necessary to connect them by rules.

The most used rules are: "If $x$ is $A$ then $y$ is B", where $x$ is the premise and $y$ is the consequence. The fuzzy binary relation between $A$ and $B$ is expressed by the membership function

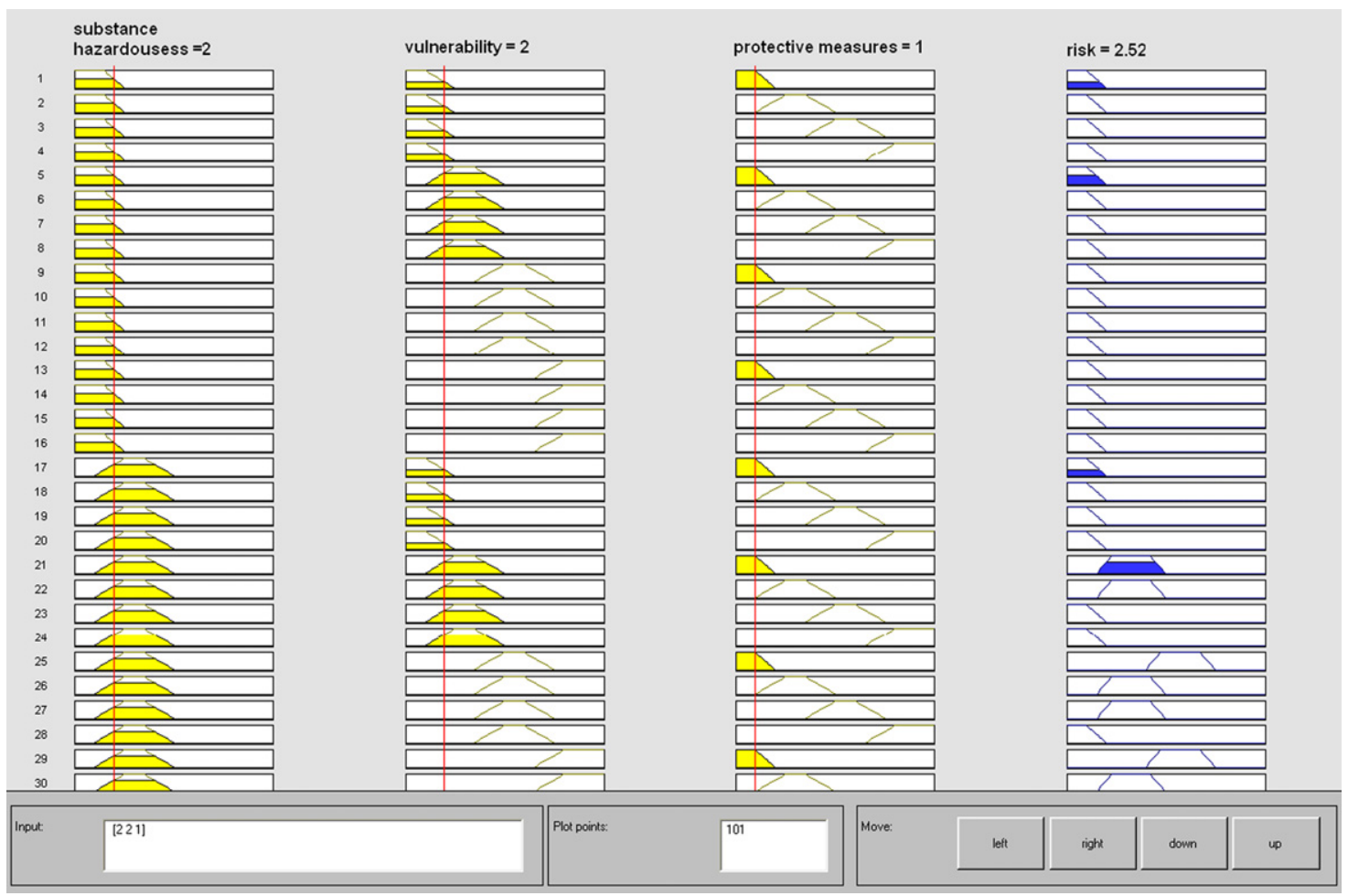

Fig. 6 - Application of the centroid method to the inputs. 
$\mu_{\mathrm{A} \rightarrow \mathrm{B}}(x, y) \in[0,1]$, which represents the level of true of the implication between $x$ and $y$. This kind of rule can also be composed of several inputs to attain one output; this is the case of the present work. Then the expression would be:

"If $\mathrm{x}$ is $\mathrm{L}$ and $\mathrm{y}$ is $\mathrm{M}$ and $\mathrm{z}$ is $\mathrm{N}$, then $\mathrm{r}$ is $\mathrm{K}$ "

As an example:

"If the hazardousness of the substance is high, and if the vulnerability is high, and if the measures are low, then the risk is high".

In order to calculate the contribution of each rule and, as a consequence, the level of true of this statement, there exist two methodologies: Correlation-Minimum Encoding and Correlation-Product Encoding (Zadeh, 1965). In the present work, the selected methodology is the one of the minimum encoding, representing the logic operator "and" as the intersection of the fuzzy subsets and thus as the minimum of the membership values:

$\mu=\min (\mu(\mathrm{x}), \mu(\mathrm{y}), \mu(\mathrm{k}))$

Rules for all the possible combinations of all the inputs with all the outputs have been established. At an early stage, a logical approach has been followed, then the rules have been adjusted in order to make them more suitable to fetch the data obtained from previous works (Orso Giacone et al., 2004).

From the setting up of the rules it is possible to obtain the relationship among the different variables. A three-dimensional view of the relation between risk, vulnerability, hazardousness of the substances can be seen in Fig. 5; the higher the vulnerability of the groundwater and soil and the hazardousness of the substances, the higher is the risk for the plant. In Fig. 6 a graphical representation of the rules is reported.

\subsubsection{Defuzzification}

Once the rules have been established, a value for each output can be obtained. This value will be the result of the union of diverse trapezoidal functions, as it is the result of the interaction of diverse rules that have been activated by the inputs. All of the fuzzy subsets assigned to each input variable are combined together to form a single fuzzy subset for each output variable. The defuzzification process, that is, the conversion of the fuzzy output set (represented as a surface) to a crisp number, can be done by using different methodologies (Max-membership principle, centroid method, medium weight, mean-max membership) (Klir and Yuan, 1996). In the present work for the defuzzification of this area, the "centroid method" has been applied in order to attain a final value (see Fig. 6). According to this method, the crisp value of the output variable is computed by finding the variable value of the centre of gravity of the membership function for the fuzzy value.

When the crisp value has been obtained it is necessary to translate it again to a linguistic parameter by using the classification in Table 3.

\section{Application of the methodology to a set of storage plants}

\subsection{Storage yards}

The test of the method has been carried out applying the methodology to a set of different storage yards of ecotoxic substances, mainly oil, in the Regione Piemonte area (Italy),

Table 4 - Main characteristics of the studied plants

\begin{tabular}{|c|c|c|c|c|}
\hline & Plant A & Plant B & Plant C & Plant D \\
\hline Substance & Gas oil & Gasoline & Benzotriazole & Gasoline \\
\hline Mobility & $\begin{array}{l}\text { It can penetrate } \\
\text { in the soil, but it } \\
\text { is not soluble } \\
\text { in water }\end{array}$ & $\begin{array}{l}\text { It is not mobile and } \\
\text { it remains into the soil. } \\
\text { Not soluble in water }\end{array}$ & It is not soluble in water & $\begin{array}{l}\text { It is not mobile and } \\
\text { it remains into the soil. } \\
\text { Not soluble in water }\end{array}$ \\
\hline Toxicity & $R 40-65-52 / 53$ & R45-65 & R53 & R45-65 \\
\hline Degradability & $\begin{array}{l}\text { Persistent in } \\
\text { anaerobic } \\
\text { conditions. } \\
\text { Not very } \\
\text { biodegradable }\end{array}$ & Very low degradability & $\begin{array}{l}\text { Very slow biodegradation in } \\
\text { aerobic conditions }\end{array}$ & Very low degradability \\
\hline Permeability & Lime/sand mixture & Lime/sand mixture & $\begin{array}{l}\text { Lime/sand and lime/ } \\
\text { pebble mixtures }\end{array}$ & Lime/sand mixture \\
\hline Depth (m) & $2-5$ & $3-6$ & 10 & 30 \\
\hline \multirow[t]{3}{*}{ Measures } & $\begin{array}{l}\text { - Interception valves } \\
\text { manually operated }\end{array}$ & - Rust preventer application & - Concrete flooring & - Containment basin \\
\hline & & $\begin{array}{l}\text { - Concrete flooring } \\
\text { - High and very high level } \\
\text { alarm and interlock } \\
\text { systems to avoid } \\
\text { tank overflow }\end{array}$ & $\begin{array}{l}\text { - Containment basin } \\
\text { - Automatic interlock system } \\
\text { with pump switch off }\end{array}$ & $\begin{array}{l}\text { - Interlock valves on piping } \\
\text { - High and very high level } \\
\text { alarm systems to avoid } \\
\text { tank overflow }\end{array}$ \\
\hline & & - Containment basin & $\begin{array}{l}\text { - Hydraulic barriers } \\
\text { - Air sparging protection system } \\
\text { - Level indicators } \\
\text { - Piezometric aquifer monitoring }\end{array}$ & \\
\hline
\end{tabular}


Table 5 - Results for toxicity, mobility and degradability from plant A

\begin{tabular}{lcc} 
Parameters & Fuzzy subset & Absolute value \\
\hline Toxicity & Medium & 6.5 \\
Mobility & Medium & 4 \\
Degradability & Low & 3 \\
\hline
\end{tabular}

where several accidental scenarios have been identified with potential impact on the environment.

As it has been said, the studied industrial plants are dedicated to the storage and subsequent trade of the products, with similar operational procedures:

- Arrival of the product from the central plant to the storage yard by pipeline or tanker.

- Unloading of the cargo to the underground or atmospheric tanks.

- Loading of the product to the tanker.

- Transport and unloading of the product to the client.

Four of these plants, different in extent and quality of the management, have been also submitted to an in-depth study, in order to verify the information collected from the risk analysis and to check the appropriateness of the method.

The surveyed plants have been labelled as Plant A, B, C and $D$ in order to keep the confidentially of the results. So as to be able to understand the results presented in the next section, a brief scheme of the main characteristics of them is presented in Table 4.

\subsection{Results}

Taking into account the information gathered during the survey of the installations, it is possible to preliminary assess the risk of release of ecotoxic substances, and identify the criticalities of the plant and its management.

In order to obtain the risk level three steps have been followed.

Table 6 - Results for permeability and depth from plant A

\begin{tabular}{llc} 
Parameters & Fuzzy subset & Absolute value \\
\hline Permeability & Slime-sand & 5 \\
Depth & Low & 3.5 \\
\hline
\end{tabular}

\section{Table 7 - Results for risk in plant A}

\begin{tabular}{llc} 
Parameters & Fuzzy subset & Absolute value \\
\hline Hazardousness & Medium-high & 6.96 \\
Vulnerability & Vulnerable & 5.62 \\
Measures & Insufficient & 1.5 \\
Risk & High & 8.61 \\
\hline
\end{tabular}

\section{Table 8 - Results for risk in all the surveyed plants}

\begin{tabular}{lcl} 
Name & Crisp value & Risk \\
\hline Plant A & 8.61 & High \\
Plant B & 3.25 & Low \\
Plant C & 5.75 & Medium \\
Plant D & 5.75 & Medium
\end{tabular}

- First, the hazardousness of the substance has been defined by giving values to the toxicity, mobility and degradability of the substance. In the plant $\mathrm{A}$, used here as a worked example, the substance was gas oil. According to what was said in the safety card, the values presented in Table 5 have been given to the parameters characterising the substance. With these values the output for the hazardousness of the substance was found to be 6.96 , which corresponds to a medium-high fuzzy subset.

- Secondly, the vulnerability of the soil and groundwater has been determined by the combination of the values given to the permeability and the depth of the ground water (see Table 6). The value obtained for the vulnerability has been 5.62 which corresponds to "Vulnerable".

- Thirdly, the level of protective and preventive measures has to be established. In this case, as it can be seen in Table 4, the measures taken are quite poor, so a value of 1.5 has been established, which corresponds to "insufficient", because the plant does not reach the minimum-risk measures indicated in Table 2.

- Finally, with the value of all the macro-variables it is possible to obtain the final value for the risk (equal to 8.61 which corresponds to high risk) as it is presented in Table 7. Following the same process for the other surveyed plants an estimation of the risk of soil pollution has been carried out. The results can be seen in Table 8 .

- As it can be seen in Fig. 6, the column on the right hand indicates the crisp value for the risk calculated by the fuzzy logic toolbox of Matlab 6.0. The translation of the crisp value into the linguistic code can be observed in Fig. 4 (previously commented).

Given the direct observation of the surveyed plants and the expert judgement, the results have shown a good agreement, this despite the apparent oversimplification of the risk function. The tool developed appears to overcome the lack of sensitivity shown by the method previously developed by the authors.

\section{Conclusions}

The application of the fuzzy logic to the assessment of risk of pollution derived from the presence of ecotoxic substances in hazard plants allows making more affordable a complex algorithm of analysis in order to obtain a risk assessment given an incomplete and reduced input data set.

The main macro-variables of the model are:

- the hazardousness of the substance,

- the vulnerability of the soil and groundwater and

- the protective and preventive measures taken.

For both sets (macro and micro-variables) fuzzy subsets and membership functions have been established. A set of rules to link all the variables has been set up and from there by the defuzzification process, a crisp value can be obtained.

The methodology developed has been successfully applied to a set of storage plants in the Regione del Piemonte (Italy). The use of this model allows a realistic preliminary assessment of the risk of accidental releases. But, it is also important to highlight the user-friendly design of the tool and the effectiveness of achieving very appropriate results in a short time 
The methodology can be used not only by public authorities but also for the same plant managers, since it is a method that allows the evaluation of the risk level of the site and also to see whether the safety measurements are suitable. This application has been developed as a preliminary risk assessment tool, able to highlight critical situations and the need for more indepth and complete analysis.

\section{R E F E R E N C E S}

Chen, G. and Pham, T., 2001, Introduction to Fuzzy Sets, Fuzzy Logic and Fuzzy Control Systems. (CRC Press, Boca Ratón, Florida).

Chen, Z., Huang, G.H. and Chakma, A., 1998, Integrated environmental risk assessment for petroleumcontaminated sites-a north American case study, Water Sci Tech, 38: 131-138.

Cox, E. 1994, The Fuzzy Systems Handbook: A Practitioner's Guide to Building, Using, and Maintaining Fuzzy Systems. (Academic Press, San Diego).

Demetri, K., Piccinini, N., Ariano, P., Orso Giacone, M. and Schellino, G., 2003, Rapid ranking criteria for the assessment of pollution risk arising from accidental releases in relevant hazard plants, In Proceedings of the ICheaP-6, the sixth Italian Conference on Chemical and Process Engineering.

Hu, Z., Chan, C.W. and Huang, G.H., 2003, A fuzzy expert system for site characterisation, Expert Syst Appl, 24: 123-131.

Khadam, I.M. and Kaluarachchi, J.J., 2003, Multi-criteria decision analysis with probabilistic risk assessment for the management of contaminated ground water, Environ Impact Assessment Rev, 23(6): 683-721.

Klir, G. J., and Yuan, B. (eds.). (1996). Fuzzy Sets, Fuzzy Logic and Fuzzy System: Selected Papers by Lotfi A. Zadeh. World Scientific Singapore.

Lark, R.M. and Bolam, H.C., 1997, Uncertainty in prediction and interpretation if spatially variable data on soils, Geoderma, 77: 263-282.
Lehn, K. and Temme, K.-H. 1996, Fuzzy classification of sites suspected of being contaminated, Ecol Modell, 85: 51-58.

Leondes, C.T. 1999, Fuzzy Theory Systems. Techniques and Applications (vol. 1). Orlanda, FL, USA: Academic Press, Inc. (Chapter 10)

Mays, M.D., Bogardi, I. and Bardossy, A., 1997, Fuzzy logic and risk-based soil interpretations, Geoderma, 77: 299-315.

Mc Bratney, A.B. and Inakwu, O.A.O., 1997, Application of fuzzy sets in soil science: fuzzy logic, fuzzy measurements and fuzzy decisions, Geoderma, 77: 85-113.

Mohamed, A.M.O. and Côté, K., 1999, Decision analysis of polluted sites-a fuzzy approach, Waste Manage, 19: 519533.

Murè, S., Demichela, M. and Piccinini, N., 2004, Risk assessment of occupational accident through fuzzy model, In Proceedings of the International Conference on Probabilistic Safety Assessment and Management, PSAM 7 (pp. 58-63)

Orso Giacone, M., Demichela, M., Piccinini, N., Pirani, R. and Ariano, P.F., 2004, Validation of the "RAES" Ranking Method. CISAP-1 1st Italian Convention on Safety \& Environment in Process Industry.

Papazoglou, I.A. 1998, Mathematical foundations of event trees, Reliab Eng Syst Saf, 61(3): 169-183.

Seveso II Directive, 1996, Council Directive 96/82/EC of the European Parliament on the control of major-accident hazards involving dangerous substances, Official Journal No. L 010 of 14 January 1997.

Seveso III Directive, 2003, Council Directive 2003/105/EC of the European Parliament amending Council Directive 96/82/EC on the control of major-accident hazards involving dangerous substances, Official Journal No. L 345 of 16 December 2003.

Uricchio, V.F., Giordano, R. and Lopez, N., 2004, A fuzzy knowledge-based decision support system for ground water pollution risk evaluation, J Environ Manage, 73: 189197.

Van der Werf, H.M.G. and Zimmer, C., 1998, An indicator of pesticide environmental impact based on a fuzzy expert system, Chemosphere, 36(10): 2225-2249.

Zadeh, L.A. 1965, Fuzzy sets, Inform Control, 8: 338-353. 